\title{
Shadowy threshold
}

THE ridiculous consequences of the threshold nuclear test-ban treaty, pressed on an unwilling world in 1974 and scheduled to take effect in April 1976, begin to make themselves known. The treaty is a strictly bilateral affair between the United States and the Soviet Union and the two parties have agreed to restrain weapons to yields not exceeding 150 kilotons. A related treaty covered peaceful nuclear explosions. Although formal ratification is still awaited, both parties have been honouring the treaty for some months.

In 1974 there was vigorous criticism of almost all aspects of the treaty in many parts of the world: a bilateral treaty was too coy; the threshold was too high for any sensible arms control purposes; the complications of geology made accurate seismic monitoring of the threshold difficult. On the last count, the period of nearly two years between proposal and enforcement was put forward by the treaty's proponents as a time when data exchange would allow accurate calibrations of test sites to be made. Certainly there was a mild flurry of activity as scientists moved between capitals clutching seismograms. But on July 4 , in the case of one of the first tests to be fired by the Soviet Union since the April deadline, there was a sufficient element of doubt in American official quarters to push the whole concept of the treaty right back into the public arena. The arguments have since continued.

No official American estimate of the yield has been forthcoming but the figures first being passed around were 100 to 200 kilotons; a later figure to be mentioned was "exactly 150 kilotons". In the midst of all this an unpublished understanding between the two powers was wheeled out, to the effect that "technical uncertainties ... may result in slight unintended breaches . . one or two such per year would not be considered a violation of the treaty". In other words, since yields can be predetermined to within a few per cent knowing the conformation of the device, at least one party to the treaty- probably the Soviet Union-intended to test right up to the threshold. Some arms control measure.

There has been much justifiable tut-tutting over these loose edges to the treaty in the past week, but little about the calculations which have helped provoke it. Yet there is a vast amount of seismic data in the public domain and this explosion will have been excellently recorded all over the world. United States government estimates take into account we know not what, but it is open to anyone else to make his or her own reasonable estimate. There are published papers giving clear recipes for how to convert a seismic signal to explosive yield, with the help of some modest knowledge of Soviet geology. And when we do the sums we can't see how the yield can be much more than 100 kilotons.

The cause of the discrepancy is an old problem. It is easiest to measure the yield seismically by observation of the so-called body waves generated by the explosion. These have the larger signal-to-noise ratio and are measured routinely. The so-called surface waves from blasts, on the other hand, are smaller and need a little more time for their analysis. But at the sort of yields we are talking about there begin to be discrepancies between yields from the same explosion measured routinely by the two techniques-and there are good theoretical grounds for favouring the surface-wave method.

In the past, the body-wave method has been known seriously to overestimate the yield. This has led to the publication of information about the yields of Soviet tests, placing them in the multi-megaton region when the yield has probably been barely a megaton. Admittedly all estimates of seismic yield are accurate only to perhaps $20 \%$. But now we see an old problem emerging to befuddle the issue of the threshold treaty, which is made to look silly right from the word go. One wonders whether the two years could not have been more profitably spent in avoiding such a hassle. 